\title{
Diagnosis and treatment of mediastinal ectopic thyroid tissue with normally located thyroid gland and primary hyperparathyroidism: a case report
}

\author{
Emir Muzurovic ${ }^{1,2}$, Brigita Smolović $^{2}$, Mirjana Miladinović ${ }^{3}$, Damir Muhović $^{2}$, Branko Čampar $^{4}$ \\ ${ }^{1}$ Department of Internal Medicine, Endocrinology Section, Clinical Center of Montenegro, Podgorica, Montenegro; ${ }^{2}$ Faculty of Medicine, \\ University of Montenegro, Podgorica, Montenegro; ${ }^{3}$ Center for Pathology, Clinical Center of Montenegro, Podgorica, Montenegro; ${ }^{4}$ Department of \\ Thoracic Surgery, Clinical Center of Montenegro, Podgorica, Montenegro \\ Correspondence to: Emir Muzurović. Department of Internal Clinic, Endocrinology Section, Clinical Centre of Montenegro; Faculty of Medicine, \\ University of Montenegro, Kruševac bb, Podgorica, Montenegro. Email: dremir@t-com.me.
}

\begin{abstract}
Mediastinal ectopic thyroid tissue (ETT) is rare entity, accounting for $1 \%$ of all mediastinal tumours. A 53-year-old lady, presented with cough and atypical chest pain. A computed tomography (CT) scan of chest showed a $95 \mathrm{~mm} \times 75 \mathrm{~mm} \times 115 \mathrm{~mm}$ tumour mass; CT guided biopsy of mediastinal mass showed ETT. Thyroid scintigraphy with Technetium-99m $\left({ }^{99 \mathrm{~m}} \mathrm{Tc}\right)$ pertechnetate showed homogenous and intense uptake in the thyroid gland (TG) lodge and in the mediastinum. Primary hyperparathyroidism (PHPT) was diagnosed during laboratory evaluation. Technetium-99m sestamibi $\left.{ }^{99 \mathrm{~m}} \mathrm{Tc}-\mathrm{MIBI}\right)$ parathyroid scintigraphy with single photon emission CT (SPECT)/CT showed uptake of radionuclide in two locations, one in the eutopic position [right inferior parathyroid gland (PTG)] and second ectopic (mediastinal). After surgery, histopathological examination confirmed mediastinal ETT and two PTG adenomas. During follow-up, laboratory analyzes were maintained within the reference range and the patient remained stable and free of symptoms and clinical signs, which supports a good prognosis. The existence of an ectopic mediastinal thyroid and an ectopic parathyroid tissue may be partly explained by a similar embryological origin. Diagnosis of ectopic thyroid and parathyroid tissues is demanding; requires a multidisciplinary team and approach using highly accurate radiological and nuclear imaging. The simultaneous existence of mediastinal ETT, nodular eutopic TG and PHPT for which two adenomas are responsible (cervical eutopic and mediastinal ectopic) is a complex diagnostic and therapeutic challenge, which we have described so far as unique. Comprehensive and multidisciplinary surgery planning is a cornerstone of treatment, when recommendations in guidelines are lacking.
\end{abstract}

Keywords: Ectopic thyroid; mediastinal mass; ectopic parathyroid; primary hyperparathyroidism; case report

Submitted Jul 24, 2020. Accepted for publication Feb 10, 2021.

doi: $10.21037 /$ gs-20-626

View this article at: http://dx.doi.org/10.21037/gs-20-626

\section{Introduction}

Mediastinal mass presents a serious clinical problem and usually raises suspicion of malignant neoplasms. Various diseases could be presented as a tumour of the mediastinum. The location and composition of the tumour are critical for making a differential diagnosis. Some of them grow from organs and tissues that are normally located in the mediastinum, while other tumours may grow from tissue that could migrate to the mediastinum (1).

Less than $10 \%$ of all masses of the mediastinum are uncommon tumors, such as lymphomas, thymic tumors, neuroendocrine tumors, germ-cell neoplasms, neurogenic, mesenchymal tissue, and endocrine tumors (1). Although rare, the most common primary endocrine tumors in the mediastinum are tumors of the parathyroid glands (PTG) or ectopic thyroid tissue (ETT), separately (1). 
It is very important to point out the difference between intramediastinal goiters and primary thyroid tumors. Intramediastinal goiters are not uncommon and usually represent direct extensions of large eutopic thyroid glands (TGs); more rarely, primary thyroid tumors (adenomas or carcinomas) may occur in the mediastinum without cervical disease (1).

Mediastinal ETT can be a serious diagnostic challenge, especially in patients with normal location and function of TG. True primary mediastinal ectopic goiters are quite rare, occurring in less than $1 \%$ of all goiters, only a few cases have been reported in literature (2-4). ETT can occur at any age but is particularly observed during childhood, adolescence and around menopause; it is more common in females with the female/male ratio being 4:1 (2).

A very important cause of persistent and recurrent primary hyperparathyroidism (PHPT) are ectopic and/ or supernumerary PTGs, which are certainly a diagnostic challenge. Phitayakorn et al. in their surgical series of patients being operated for PHPT verified ectopic PTGs in $16 \%$ of patients (5). Ectopic superior PTGs are due to pathological displacement from a normal anatomic position, whereas ectopic inferior PTGs are likely due to abnormal migration during embryogenesis, and are most frequently found in the anterior mediastinum (5). Although, in most cases ectopic parathyroid tissue is associated with PHPT, it can also be afunctional; all functioning parathyroid tissue in the mediastinum should be treated surgically, and a complete neck exploration should be done when possible to exclude other PTG involvement (1).

Although similar to the above cases (2-5), we will discuss here the unique case of coexistence of mediastinal ETT and PHPT due to two adenomas, one in an eutopic position on the neck and the other ectopic in the anterior mediastinum positioned adjacent to the ETT.

We present the following article in accordance with the CARE reporting checklist (6) (available at http://dx.doi. org/10.21037/gs-20-626).

\section{Case presentation}

We describe the case of a previously healthy 53-yearold female who was admitted to the outpatient clinic because of cough and atypical chest pain. She began to feel these symptoms two months before, without any other complaints and clinical signs. Physical examination was normal. The patient had noncontributory family history and no previous surgical history. Chest $\mathrm{x}$-ray showed a large superior mediastinal shadow. A computed tomography (CT) scan of the chest and neck (with double contrast revealed) was obtained and showed a $95 \mathrm{~mm} \times 75 \mathrm{~mm} \times$ $115 \mathrm{~mm}$, sharply outlined heterogeneous tumour mass with several calcifications in the central parts, in upper anterior mediastinum. The mass was separated from TG and exerted a mild impression on the thoracic aorta, pulmonary artery and trachea (Figure 1).

A CT guided biopsy was performed and the histopathological examination revealed thyroid tissue, smaller and larger follicles filled with colloid with thyrocytes of uniform nuclei and free of atypia. This initial diagnosis was followed by a thyroid ultrasound (US) which confirmed normal location of TG, multiple nodules with prominent nodule in left lobe of TG (dimensions $19 \mathrm{~mm} \times 16 \mathrm{~mm} \times$ $18 \mathrm{~mm}$ ), categorized as low risk for malignancy (according to nodule sonographic patterns); guided fine needle aspiration (FNA) was performed, cytology showed thyrocytes without atypia.

\section{Investigation}

At the endocrinology department, additional investigation was conducted. Initial biochemical and hormonal investigation showed levels of thyroid-stimulating hormone (TSH $0.87 \mathrm{mIU} / \mathrm{L}$ ), free thyroxine (fT4 $10.7 \mathrm{pmol} / \mathrm{L}$ ) and free triiodothyronine (fT3 $4.3 \mathrm{pmol} / \mathrm{L}$ ) within the reference range. Anti-thyroid peroxidase (anti-TPO), thyroglobulin antibodies (TgAt) and calcitonin level were also normal. Additional laboratory evaluation, parathyroid hormone (PTH) $152 \mathrm{pg} / \mathrm{mL}$ [normal range (NR) 10-65 pg/mL], serum calcium (Ca) $3.11 \mathrm{mmol} / \mathrm{l}$ (NR 2.2-2.55 mmol/L), ionized $\mathrm{Ca}\left(\mathrm{Ca}^{++}\right) 1.52 \mathrm{mmol} / \mathrm{L}$ (NR $1.10-1.35 \mathrm{mmol} / \mathrm{L}$ ), phosphate (Phos) $0.76 \mathrm{mmol} / \mathrm{L}$ (NR 0.97-1.45 mmol/L), 24-hour urinary Ca $9.51 \mathrm{mmol} / \mathrm{L}$ (NR $2.50-7.50 \mathrm{mmol} /$ 24-hour), and calculated fractional excretion of $\mathrm{Ca} 2.89 \%$ $(>1 \%)$ were in favor of primary hyperparathyroidism (PHPT). Further examination verified normal bone mineral density, and slightly decreased renal function (creatinine clearance $85 \mathrm{~mL} / \mathrm{min} / 1.73 \mathrm{~m}^{2}$ ).

For preoperative localization of hyperfunctional parathyroid and thyroid tissue, nuclear imaging techniques were used. Radionuclide thyroid scintigraphy with Technetium-99m $\left.{ }^{99 \mathrm{~m}} \mathrm{Tc}\right)$ pertechnetate showed homogenous and intense uptake in the TG lodge and in the mediastinum (CT diagnosed mass region) (Figure 2). This was followed by dual wash technetium- $99 \mathrm{~m}$ sestamibi $\left.{ }^{99 \mathrm{~m}} \mathrm{Tc}-\mathrm{MIBI}\right)$ parathyroid scintigraphy with single photon emission 

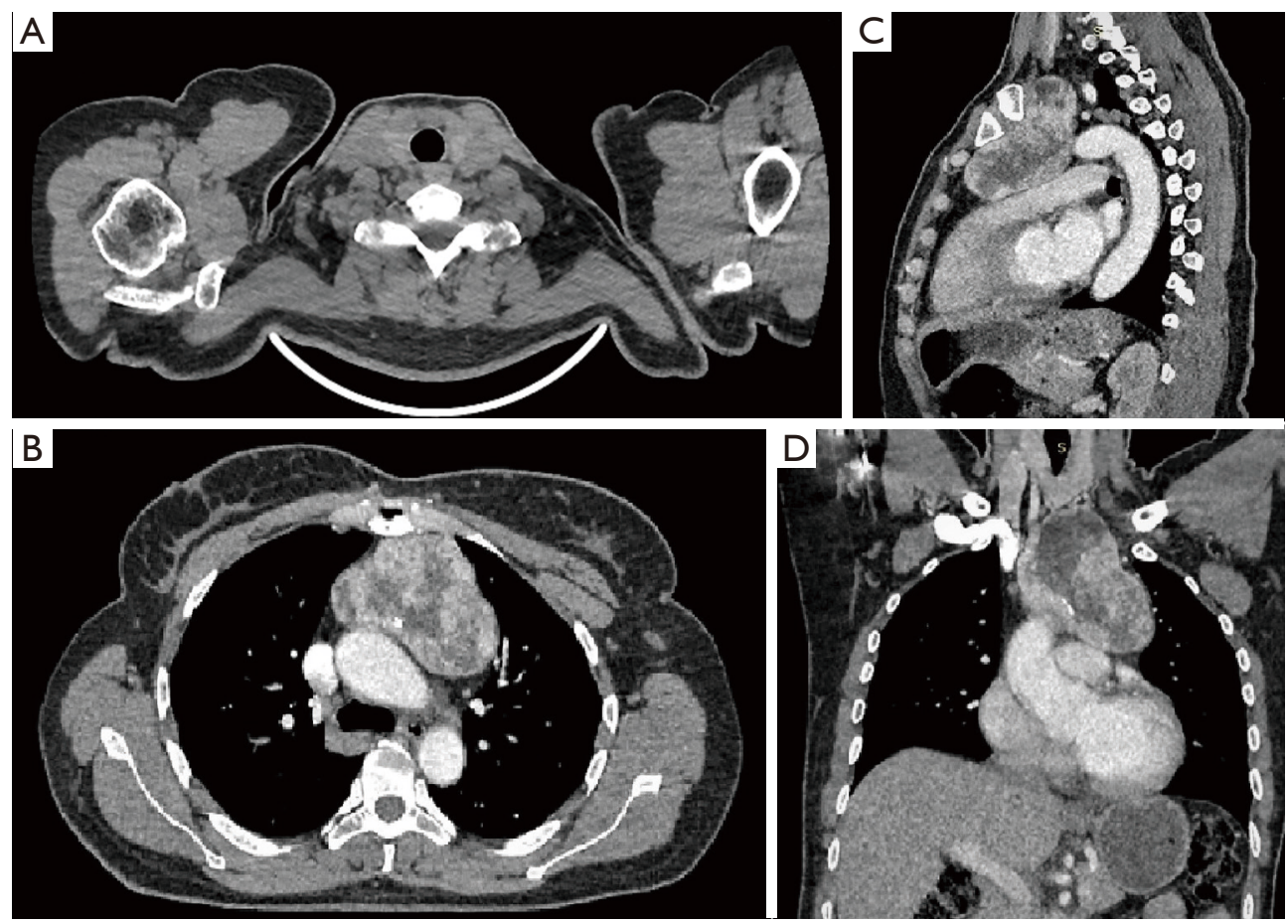

Figure 1 Computed tomography (CT) scan of the chest and neck showed normally located thyroid gland (TG) (A) and sharply outlined heterogeneous tumour mass $(95 \mathrm{~mm} \times 75 \mathrm{~mm} \times 115 \mathrm{~mm})$ in upper anterior mediastinum, separated from TG and exerted a mild impression on the thoracic aorta, pulmonary artery and trachea—axial view (B), sagittal view (C) and coronal view (D).

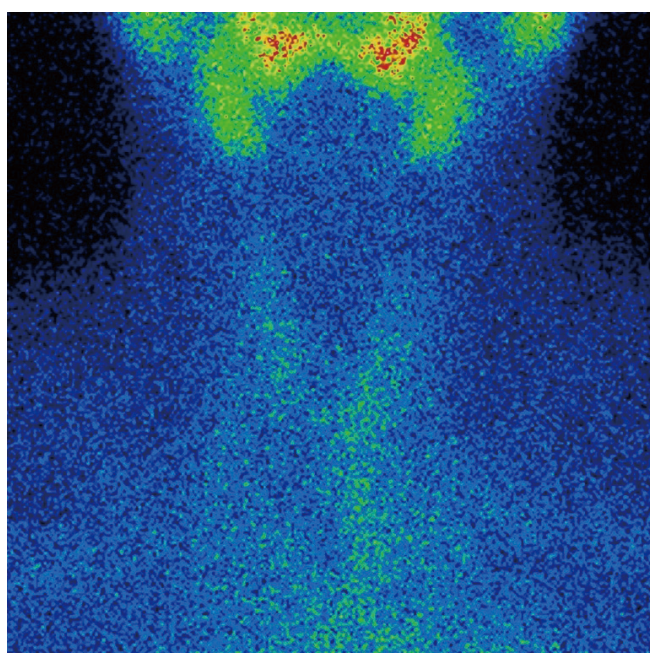

Figure 2 Thyroid gland (TG) scintigraphy with Technetium-99m $\left({ }^{99 \mathrm{~m}} \mathrm{Tc}\right)$ pertechnetate showed homogenous and intense uptake in the TG lodge and in the mediastinum.

CT (SPECT)/CT with uptake of tracer in two locations: behind the lower half of the right lobe of the TG and in the region of the retrosternal mass on the left side in the level of the upper third of the sternum (Figure 3). Diagnosis of the ETT with normally located euthyroid nodular TG and PHPT with increased ${ }^{99 \mathrm{~m}} \mathrm{Tc}-\mathrm{MIBI}$ uptake in two foci related to hyperfunctional parathyroid tissue, was confirmed.

\section{Treatment}

However, owing to its rarity and rather unclear management guidelines, this case needed a multidisciplinary team approach. Subsequently, endocrinology, thoracic surgery and radiology experts were involved. With a general consensus, the patient was planned for a complete resection of the ectopic thyroid tissue mass with total thyroidectomy, parathyroidectomy via mediastinal and cervical exploration and thymectomy.

A partial sternotomy and Kocher cervicotomy were performed and intra-operatively, a giant mass was identified that occupied the entire upper anterior mediastinum with displacement of thoracic aorta, pulmonary artery and trachea (Figure 4). Complete removal of mediastinal mass (multinodular, well circumscribed and had firm in consistency), total thyroidectomy, parathyroidectomy and 

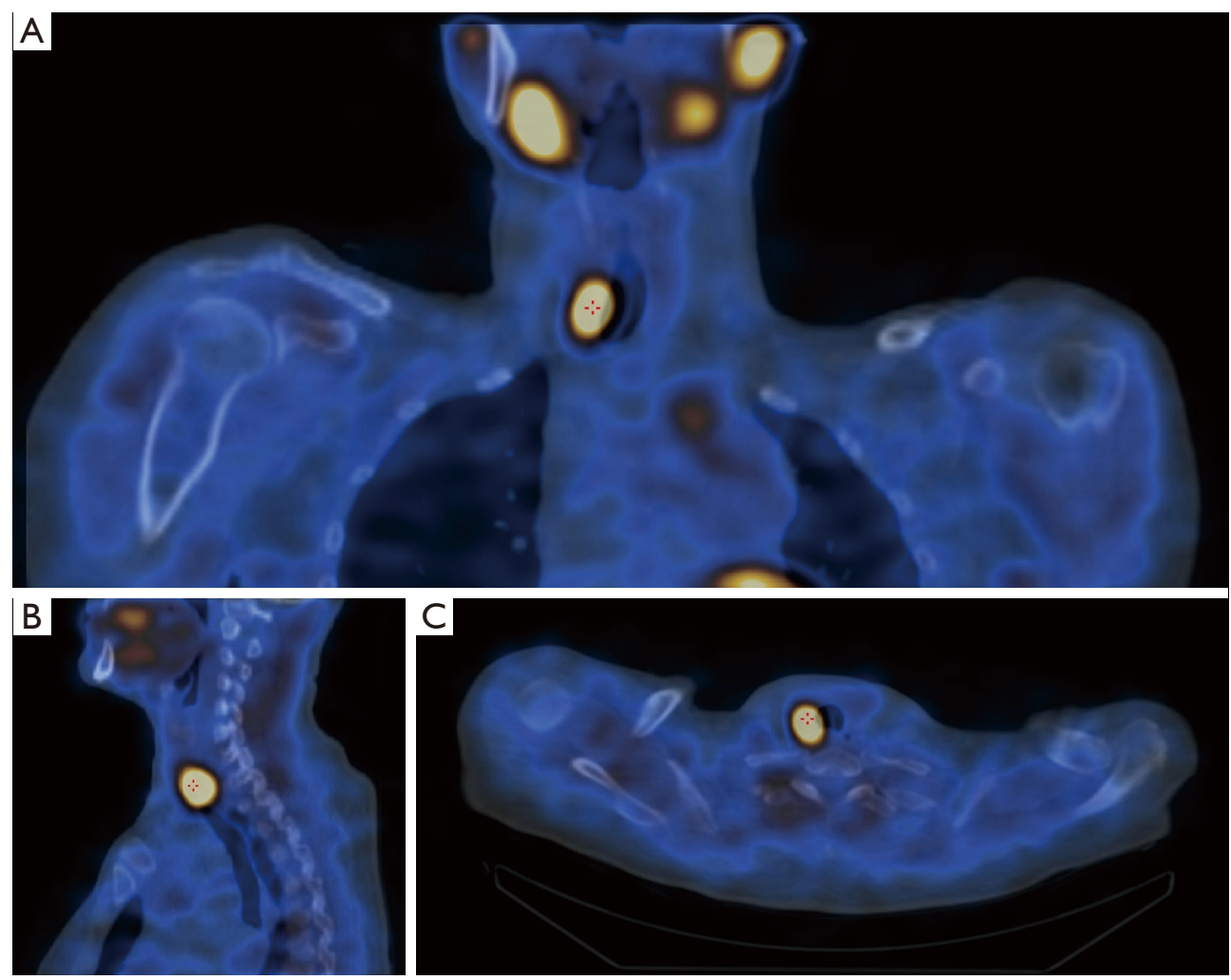

Figure 3 Dual wash Technetium-99m sestamibi $\left({ }^{99 m} \mathrm{Tc}-\mathrm{MIBI}\right)$ parathyroid scintigraphy with single photon emission computed tomography scan (SPECT/CT) with uptake of tracer in two locations: behind the lower half of the right lobe of the thyroid gland (TG) (coronal view A, sagittal view B, axial view $\mathrm{C}$ ) and in the region of the retrosternal mass on the left side in the level of the upper third of the sternum (A).

thymectomy was achieved. No connection was present between mediastinal mass and normally localized TG. The tissue samples were sent for histopathological examination, which revealed colloid goiter with cystic degeneration of ETT and TG, two PTG adenomas and normal thymic tissue; all tissues were negative for malignancy (Figure 5).

\section{Outcome and follow-up}

Immediately, postoperatively the patient was treated with L-thyroxine $(87.5 \mathrm{mcg}$, the dose was calculated by body weight) and oral calcium carbonate $(1,000 \mathrm{mg}$ twice-daily) with frequent monitoring of the $\mathrm{Ca}^{++}$, Phos and PTH levels which were within the reference range from the first postoperative day. Postoperatively the patient remained stable and was discharged on the seventh post-operative day.

After recovery, the patient remained free of symptoms and clinical signs 3 months after surgery; after increasing the dose of L-thyroxin to $100 \mathrm{mcg}$ once-daily, TSH (3.89 $\mathrm{mIU} / \mathrm{L})$ and fT4 (11.7 pmol/L) values were maintained within the NR, 12-week of follow up after surgery. Also $\mathrm{Ca}(2.35 \mathrm{mmol} / \mathrm{L}), \mathrm{Ca}^{++}(1.21 \mathrm{mmol} / \mathrm{L})$, Phos $(0.99 \mathrm{mmol} / \mathrm{L})$ and PTH $(49 \mathrm{pg} / \mathrm{mL})$ values are also within the NR during follow up. The patient is currently following-up at our hospital's endocrinology clinic, without complications.

We have described the most important facts from this case report in timeline (Figure 6).

All procedures performed in studies involving human participants were in accordance with the ethical standards of the institutional and/or national research committee(s) and with the Helsinki Declaration (as revised in 2013). Written informed consent was obtained from the patient.

\section{Discussion}

We have described a unique case of a patient with a combination of ETT in the anterior mediastinum and TG in the anatomical lodge, and PHPT due to two adenomas, one in an eutopic position on the neck and the other 

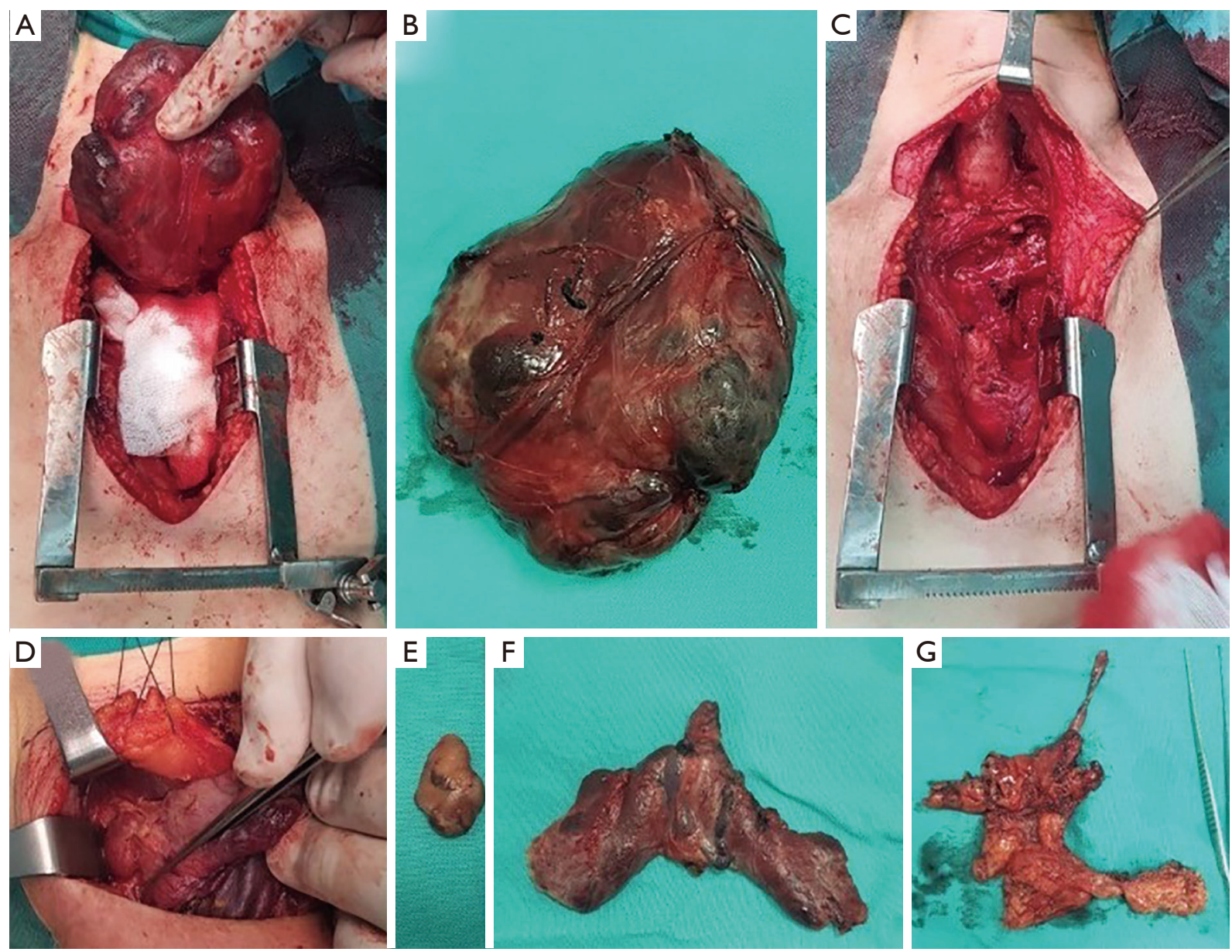

Figure 4 Partial sternotomy and Kocher cervicotomy and giant mass in the upper anterior mediastinum-mediastinal ectopic thyroid tissue (ETT) (A, B). Operation field after ETT removal (C). Identification and removal of parathyroid gland (PTG) adenomas (D, E). Eutopic nodular thyroid gland (TG) (F) and thymus (G) after complete thyroidectomy and thymectomy.

ectopic in the anterior mediastinum, positioned adjacent to the ETT.

ETT can co-exist with eutopic thyroid, even if in the majority of cases it occurs without cervical location of the thyroid (7). Mediastinal ETT without connection to the normally located TG in the neck is extremely rare, and only a few cases have been reported in the literature until now $(2,3,8)$.

ETT results from a developmental abnormality during the migration of the thyroid tissue which primarily appears as a duct like invagination of the endoderm in the floor of the pharynx to its final position in the neck (9). That leads to presence of thyroid tissue at sites other than its normal cervical location (10). The molecular mechanisms implicated in this dysgenesis process are not fully elucidated but are discussed in many case reports (3).
Santangelo et al. in their retrospective analysis of patients undergoing surgical treatment for thyroid disease, identified ETT in $0.9 \%$ patients and the anatomical site of ETT was as follows: lateral cervical in $21.4 \%$, along the thyroglossal duct in $21.4 \%$, mediastinal in $17.9 \%$, lingual in $17.9 \%$, sublingual in $10.7 \%$, and submandibular in $10.7 \%$ (7). As we mentioned, our case patient presented with rare mediastinal localization of ETT with the simultaneous existence of a normal functioning TG, in the usual position in the neck.

The fourth pharyngeal pouch gives rise to the superior PTGs, which have a much shorter embryologic descent than their inferior counterparts, and as they lose their attachment with the pharyngeal wall, they attach to the posterior surface of the caudally migrating TG (10). The inferior PTGs arise from the third pharyngeal pouch endoderm and have a common origin and migration 

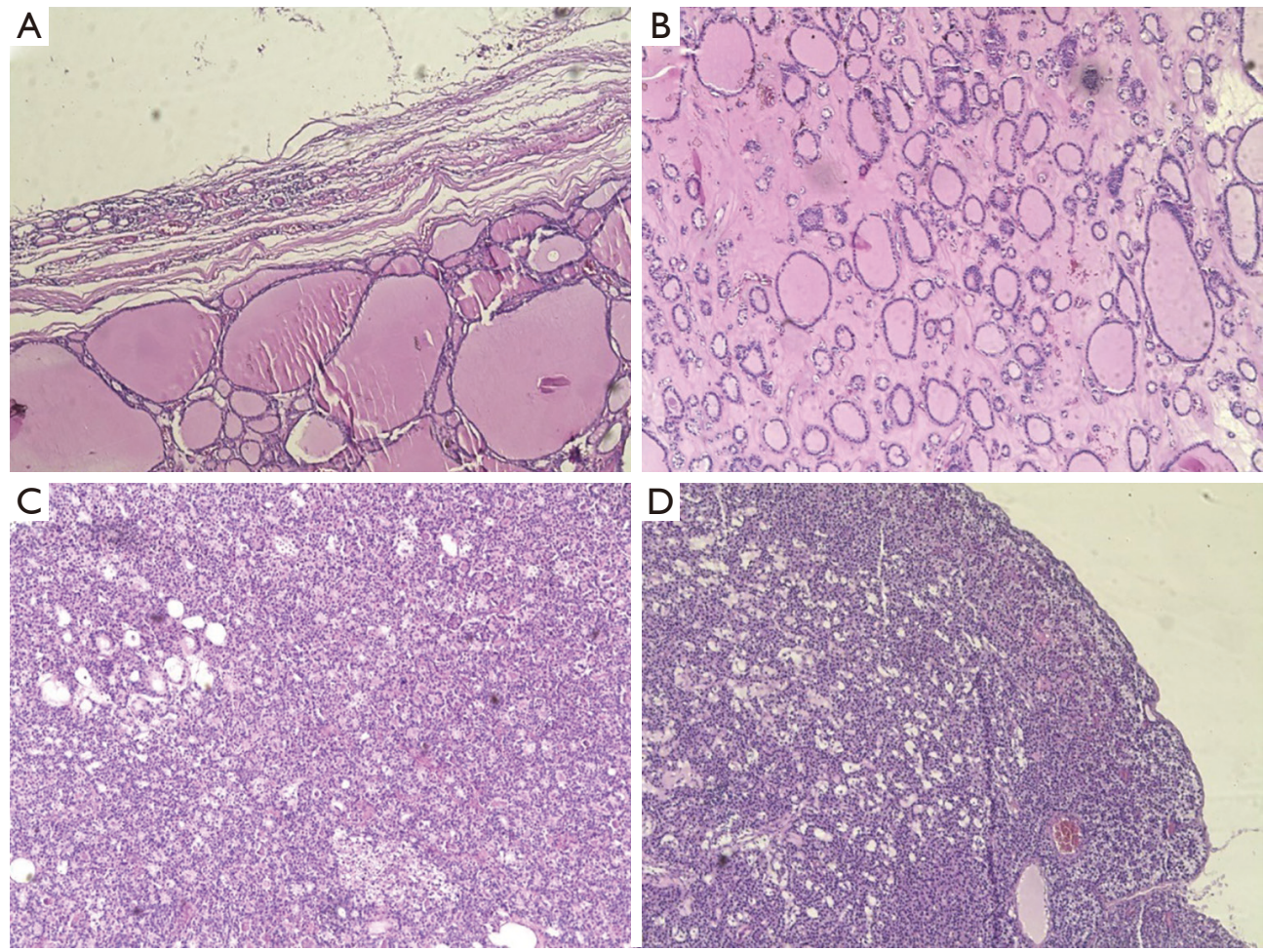

Figure 5 Histopathology report: colloid goiter with cystic degeneration of mediastinal ectopic thyroid tissue (ETT) (A), eutopic thyroid gland (TG) (B), ectopic mediastinal parathyroid gland (PTG) adenoma (C), and eutopic right inferior PTG adenoma (D). Hematoxylin and eosin stain (magnification $\times 100$ ).

with the thymus (10). Ectopic superior PTGs are due to pathological displacement from a normal anatomic position, whereas ectopic inferior PTGs are likely due to abnormal migration during embryogenesis, and are most frequently found in the anterior mediastinum (5). Ectopic superior PTG are most frequently found in the tracheoesophageal groove ( $43 \%$ of cases) and less commonly in retroesophageal (22\%), posterosuperior mediastinal (14\%), paraesophageal (7\%), intrathyroidal (7\%) positions or in the carotid sheath (7\%) (5). Ectopic inferior PTGs are most frequently found in the anterior mediastinum, in association with the thymus gland; other less common sites are anterosuperior mediastinal $(22 \%)$, intrathyroidal $(15-22 \%)$, within the thyrothymic ligament (17\%) and rarely submandibular (9\%) (5). In our case, with the presence of the lower right PTG adenoma, another ectopic mediastinal functional adenoma was associated with ETT.

Symptoms are usually related to size and location of the ETT as well as associated endocrine dysfunctions. ETT in the anterior mediastinum is usually asymptomatic and consequently is discovered incidentally, until the structures in the chest remain uninvolved; on the contrary, the patients refer dyspnea, cough and a sensation of retrosternal mass (4). Symptoms are usually related to size and location of the ETT as well as associated endocrine dysfunctions. The most frequent clinical presentation in some series are: palpable mass $(68 \%)$, asymptomatic (21\%), dyspnea (14\%) and mediastinal syndrome (7\%) (7) According to these data, our patient presented with atypical symptoms such as cough and atypical chest pain. Also, despite the diversity of clinical presentations, in our case the PHPT presented as asymptomatic form.

ETT should be suspected when a hyperdense mass (with sustained intravenous contrast enhancement and which may also contain cystic of calcific foci) within mediastinum is detected by CT scan (11). Mentioned CT scan, and also magnetic resonance imaging (MRI) and US may be useful for the evaluation of ETT extension, however a radionuclide TG scintigraphy with ${ }^{99 \mathrm{~m}} \mathrm{Tc}$ pertechnetate is the best diagnostic test for ETT (2). Iodine-123 SPECT/ 


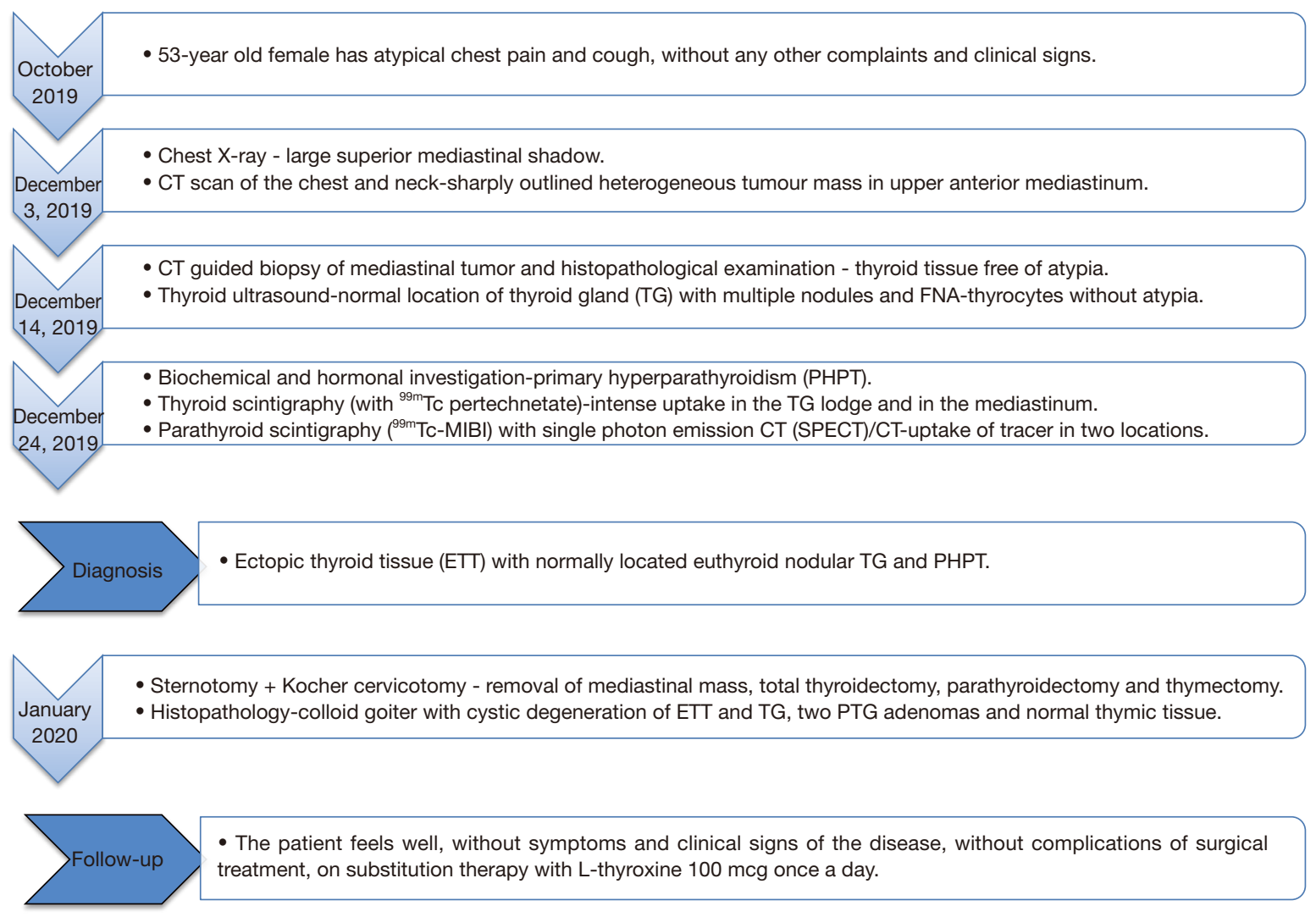

Figure 6 Timeline of diagnosis, treatment and follow-up for a patient with ectopic thyroid tissue (ETT) with normally located thyroid gland (TG) and primary hyperparathyroidism (PHPT).

CT can be useful for both functional and anatomic characterization of suspected ETT to guide medical management of hypothyroidism, rarely hyperthyroidism, in the patients with ETT (11). Radiological methods and procedures in our case (TG US, CT scan and CT guided biopsy) indicated the existence of ETT in the anterior mediastinum and above it separated TG in the usual cervical location; ${ }^{99 \mathrm{~m}} \mathrm{Tc}$ pertechnetate thyroid scintigraphy proved dominantly homogeneous radionuclide uptake in the TG lodge and upper mediastinum.

Though extremely rare, the peculiarity of our case is not only the finding of mediastinal ETT with eutopic TG. Uniqueness is the simultaneous existence of mediastinal ETT and PHPT for which two adenomas were responsible (cervical eutopic and mediastinal ectopic). To our knowledge this has not been described in the literature. Following the biochemical diagnosis of PHPT, ${ }^{99 \mathrm{~m}} \mathrm{Tc}-\mathrm{MIBI}$ scan played a key role in localizing of hyperfunctional parathyroid tissue; the increased uptake of radionuclides in two loci was found with a histopathological finding that confirmed the PTGs adenomas. Ectopic and/or supernumerary PTG are important diagnostic challenge, and a major cause of persistent and recurrent PHPT; about $60 \%$ of the supernumerary parathyroid adenomas are located in the mediastinum, the majority being in the thymus (12). Localization diagnostics in PHPT is usually not easy, especially when ectopic PTGs exist; different modalities are used in diagnostics and present different sensitivity: neck US $27-89 \%,{ }^{99 \mathrm{~m}}$ Tc-MIBI scan $54-100 \%$ (mostly $80-90 \%$ ), CT $65 \%$, MRI 75-78\%, SPECT 95\%, dual-phase ${ }^{99 \mathrm{~m}}$ Tc$\mathrm{MIBI}^{99 \mathrm{~m}} \mathrm{TcO}_{4}^{-}$planar scintigraphy (combination with US, and SPECT) $96 \%$ and FNA cytology $70 \%$ (13).

For mediastinal mass and in particular for ETT, surgery as first-line therapy should be considered because of the high risk of compression of the surrounding organs (4). The surgical excision of mediastinal ETT is also 
recommended to obtain, at the same time, the definitive diagnosis and treatment (4). In addition, recommended treatment in a state of thyroid in situ is surgical excision of mediastinal ETT, associated to total thyroidectomy (5). Thyroidectomy is justified by the frequent nodular diseases related to ectopia; ETT consist of a rare disease potentially undergoing the same pathological changes of a eutopic TG (7). Also, parathyroid surgery requires experienced parathyroid surgeons; exploration for PHPT requires a complete, meticulous surgical dissection to identify all PTGs and to search for possible accessory tissue in selected cases (13).

Diagnostic approaches and surgical treatment could be based on the similarities of the described cases (2-4,14-18). Accordingly, CT (2,3,15-17), ${ }^{99 \mathrm{~m}} \mathrm{Tc}$ pertechnetate scintigraphy $(3,14), M R(14)$ and histological confirmation using CT guided biopsy $(15,16)$ or EBUS (endobronchial US)-transbronchial needle aspiration (18), were used in the diagnosis of mediastinal ETT. Furthermore, authors have described the transthoracic surgical approach as dominant (2-4), although there is a case of removal of mediastinal ETT through a cervical approach (15). Accurate PTG tissue identification and selection of the optimal surgical method are important. Conventionally, median sternotomy and upper partial sternotomy have been used for surgical excision of mediastinal parathyroid adenomas that are difficult to excise using the cervical approach (19).

Based on the successful treatment of case and data from literature, we consider clinical examination combined with imaging methods (US, CT scanning and ${ }^{99 \mathrm{~m}} \mathrm{Tc}$ pertechnetate scintigraphy) and CT guided biopsy (in some cases), as the most important steps in the pre-operative diagnosis of ETT. The importance of a broader view on the mediastinal ETT entity in certain circumstances (e.g., in this case coexistence with PHPT) is the main advantage of our case. Consequently, additional diagnostics [US, CT, ${ }^{99 \mathrm{~m}} \mathrm{Tc}-\mathrm{MIBI}$ parathyroid scintigraphy or choline positron emission tomography $(\mathrm{PET}) / \mathrm{CT}$ ] should be performed, in order to exclude the existence of a hyperfunctional ectopic PTG. The absence of similar cases to date is a major limitation, and a universal diagnostic and surgical approach cannot be defined on the basis of a single case. Consequently, there are no clear recommendations in the guidelines to clarify similar clinical dilemmas. This issue may lead in the future to the possible development of recommendations for additional evaluation of PTG diseases in patients with ETT, with the aim of optimal surgical treatment.

Finally, given the existence of multiple adenomas, the possibility that this is a familial form of PHPT is not ruled out. The absence of a transient hypoparathyroidism after removal of the two hyperfunctioning PTGs argues in favor of such hypothesis.

\section{Learning points}

* Ectopic thyroid tissue (ETT) is a serious challenge during differential diagnosis of mediastinal tumor, especially in patients with normal location and function of thyroid gland (TG).

* An explanation for the presence of ETT, takes into account some defects in the differentiation, migration or growth of thyroid tissue, which happened during the embryological development.

* The existence of ETT in mediastinum and an ectopic parathyroid adenoma may be partly explained by a similar embryological origin, as well as by a similar migration of cells/tissues to the final, normal or ectopic localization.

* Diagnosis of ectopic thyroid and parathyroid tissues is challenging and requires a multidisciplinary team and approach using highly accurate radiological and nuclear imaging techniques.

* The recommended treatment is surgical excision of mediastinal ETT, associated with total thyroidectomy; parathyroid surgery requiring "high-volume" parathyroid surgeons.

\section{Conclusions}

The existence of the mediastinal ETT and an ectopic PTG (adenoma) may be partly explained by a similar embryological origin, as well as by a similar migration of cells/tissues to the final, normal or in this case ectopic localization. Diagnosis of ectopic thyroid and parathyroid tissues is demanding; requires a multidisciplinary team and approach using highly accurate radiological and nuclear imaging.

The simultaneous existence of mediastinal ETT, nodular eutopic TG and PHPT for which two adenomas are responsible (cervical eutopic and mediastinal ectopic) is a complex diagnostic and therapeutic challenge, which we have described so far as unique. 


\section{Acknowledgments}

Funding: None.

\section{Footnote}

Reporting Checklist: The authors have completed the CARE reporting checklist. Available at http://dx.doi.org/10.21037/ gs-20-626

Peer Review File: Available at http://dx.doi.org/10.21037/gs20-626

Conflicts of Interest: All authors have completed the ICMJE uniform disclosure form (available at http://dx.doi. org/10.21037/gs-20-626). The authors have no conflicts of interest to declare.

Ethical Statement: The authors are accountable for all aspects of the work in ensuring that questions related to the accuracy or integrity of any part of the work are appropriately investigated and resolved. All procedures performed in studies involving human participants were in accordance with the ethical standards of the institutional and/or national research committee(s) and with the Helsinki Declaration (as revised in 2013). Written informed consent was obtained from the patient.

Open Access Statement: This is an Open Access article distributed in accordance with the Creative Commons Attribution-NonCommercial-NoDerivs 4.0 International License (CC BY-NC-ND 4.0), which permits the noncommercial replication and distribution of the article with the strict proviso that no changes or edits are made and the original work is properly cited (including links to both the formal publication through the relevant DOI and the license). See: https://creativecommons.org/licenses/by-nc-nd/4.0/.

\section{References}

1. Macchiarini P, Ostertag H. Uncommon primary mediastinal tumours mediastinal tumours. Lancet Oncol 2004;5:107-18.

2. Regal M, Kamel MM, Alyami H et al. Mediastinal ectopic thyroid mass with normal thyroid function and location: Case report. Int J Surg Case Rep 2018;52:5-7.

3. Thuillier F, Venot J. Ectopic thyroid tissue in the anterior mediastinum with a normally located gland: a case report. Ann Endocrinol (Paris) 2012;73:34-6.

4. Metere A, De Giacomo T, Vergine M, et al. Diagnosis and management of a mediastinal ectopic thyroid laying on the right bronchus: case report and review of literature. BMC Surg 2018;18:19.

5. Phitayakorn R, McHenry CR. Incidence and location of ectopic abnormal parathyroid glands. Am J Surg 2006;191:418-23.

6. Riley DS, Barber MS, Kienle GS, et al. CARE guidelines for case reports: explanation and elaboration document. J Clin Epidemiol 2017;89:218-35.

7. Santangelo G, Pellino G, De Falco N, et al. Prevalence, diagnosis and management of ectopic thyroid glands. Int J Surg 2016;28:S1-6.

8. Wang J, Fang J. Ectopic thyroid mass in the left lateral neck and anterior mediastinum: a case report. J Med Case Rep 2014;8:351.

9. Guerra G, Cinelli M, Mesolella M, et al. Morphological, diagnostic and surgical features of ectopic thyroid gland: a review of literature. Int J Surg 2014;12:S3-11.

10. Fancy T, Gallagher D 3rd, Hornig JD. Surgical anatomy of the thyroid and parathyroid glands. Otolaryngol Clin North Am 2010;43:221-7, vii.

11. Hummel J, Wachsmann J, Carrick K, et al. Ectopic Thyroid Tissue in the Mediastinum Characterized by Histology and Functional Imaging with I-123 SPECT/ CT. Case Rep Radiol 2017;2017:9084207.

12. Uludag M, Isgor A, Yetkin G, et al. Supernumerary ectopic parathyroid glands. Persistent hyperparathyroidism due to mediastinal parathyroid adenoma localized by preoperative single photon emission computed tomography and intraoperative gamma probe application. Hormones (Athens) 2009;8:144-9.

13. Noussios G, Anagnostis P, Natsis K. Ectopic parathyroid glands and their anatomical, clinical and surgical implications. Exp Clin Endocrinol Diabetes 2012;120:604-10.

14. Uludag M, Isgor A, Yetkin G, et al. Ectopic mediastinal thyroid tissue: cervical or mediastinum originated?. BMJ Case Rep 2009;2009:bcr09.2008.1004.

15. Walz PC, Iwenofu OH, Essig GF. Ectopic mediastinal goiter successfully managed via cervical approach: case report and review of the literature. Head Neck 2013;35:E94-7.

16. Abdel Aal M, Scheer F, Andresen R. Ectopic mediastinal thyroid tissue with a normally located thyroid gland. Iran J 
Radiol 2015;12:e7054.

17. Zheng W, Tan J, Liu T. Coexistence of non-functional ectopic thyroid tissue and a normal thyroid: A case report. Exp Ther Med 2013;6:1059-61.

18. Roh E, Hong ES, Ahn HY, et al. A case of mediastinal

Cite this article as: Muzurović E, Smolović B, Miladinović M, Muhović D, Čampar B. Diagnosis and treatment of mediastinal ectopic thyroid tissue with normally located thyroid gland and primary hyperparathyroidism: a case report. Gland Surg 2021;10(4):1532-1541. doi: 10.21037/gs-20-626 ectopic thyroid presenting with a paratracheal mass. Korean J Intern Med 2013;28:361-4.

19. Kitada M, Yasuda S, Nana T, et al. Surgical treatment for mediastinal parathyroid adenoma causing primary hyperparathyroidism. J Cardiothorac Surg 2016;11:44. 